\title{
Estudo das Tensões Residuais de Juntas Soldadas de Aço API 5L X80
}

\author{
(Residual Stress Study of API 5L X80 Steel Welded Joints )
}

\author{
Bruno Allison Araújo ${ }^{1}$, Maria do Socorro Silva Sousa Lima², Theophilo Moura Maciel ${ }^{3}$, Antonio Almeida Silva ${ }^{4}$, Emanuel Pereira \\ Soares 5 \\ 1, 2, 3, 4, 5 Universidade Federal de Campina Grande, Programa de Pós-graduação em Ciência e Engenharia de Materiais, Campina \\ Grande,Paraiba,Brasil.bengmec@yahoo.com.br',mssslima@hotmail.com²,theo@dem.ufcg.edu.br ${ }^{3}, a l m e i d a @ d e m . u f c g . e d u$. \\ br $r^{4}$,manueps@yahoo.com.br ${ }^{5}$
}

\begin{abstract}
Resumo
Este trabalho teve por objetivo determinar os niveis de tensões residuais decorrentes de processos de soldagem em juntas soldadas de um aço API 5 L X80. Inicialmente foram executados os procedimentos de soldagem das juntas utilizando os processos de soldagem eletrodo revestido - Shielded Metal Arc Welding (SMAW) e eletrodo de tungstênio com proteção gasosa - Gas Tungsten Arc Welding $(G T A W)$, variando-se os consumiveis utilizados e empregando-se uma temperatura de interpasse de $175^{\circ} \mathrm{C}$, obtendo-se, desta maneira, três juntas soldadas. Foram avaliadas as regiões superiores e inferiores das juntas, determinando-se os niveis de tensões residuais transversais e longitudinais. As medidas de tensão residual foram realizadas por difratometria de raios-x através de um difratômetro portátil e respectivo software para análise dos resultados. Para a região superior das juntas soldadas, foi observado que quanto mais elevado for o aporte térmico mais compressivas foram os niveis de tensões residuais transversais, e mais deslocadas ficaram os picos de tensões trativas. Na região inferior das juntas soldadas, foi verificado que para maiores aportes térmicos, maiores foram os niveis de tensões residuais trativas na região do Metal de Solda (MS) e menor foi o nível de tensões residuais trativas na Zona Termicamente Afetada (ZTA).
\end{abstract}

Palavras-chave: Aço API 5 L X80, Juntas soldadas, Tensões residuais, Difratometria de raios- $x$.

\begin{abstract}
This study aimed to determine the levels of residual stresses due to welding processes in welded joints of API $5 L X 80$ steel. Initially were executed the welded joint using the Shielded Metal Arc Welding (SMAW) and Gas Tungsten Arc Welding (GTAW) processes, with different consumables and employing an interpass temperature of $175^{\circ} \mathrm{C}$. Three different welded joints were obtained. The residual stress measurements were carried out by $x$-ray diffraction using a portable diffractometer and software for analyzing the results. In the upper region, it was observed that to higher heat inputs the residual stresses levels were more compressive and more displaced were the tensile stresses peaks. In the lower region of the welded joints, it was found that for higher heat input, were higher levels of tensile residual stresses in the region of the Weld Metal (WM) and the lower the level of tensile residual stresses in the Heat Affected Zone (HAZ).
\end{abstract}

Key-words: API $5 L$ X80 steel, Welded joints, Residual stresses, X-ray diffraction.

\section{Introdução}

Com a evolução tecnológica dos vários segmentos industriais, principalmente nas últimas décadas, ocorreu um aumento da demanda de transporte de gás natural e petróleo por tubulações. Logo, elevados investimentos tem sidos realizados na montagem de novas redes de transporte e distribuição de hidrocarbonetos. Além disso, a necessidade de canalizar insumos provenientes de locais de extração recém descobertos e de abastecer centros consumidores com demanda em ascensão, também tem contribuído para o crescimento da rede dutoviária $[1,2]$.

Recebido em 18/03/2013. Texto final em 29/04/2013.

Trabalho apresentado no CONSOLDA 2012.
Dentre os aços empregados para as novas linhas de distribuição utilizadas no Brasil destaca-se o aço API 5L X80. Esses são aços ARBL (Alta Resistência e Baixa Liga) de fabricação recente que foram desenvolvidos para atender os requisitos de alta resistência mecânica associado com alta tenacidade para a fabricação de tubulações para o transporte de petróleo e gás. No Brasil, este aço está sendo empregado para as novas linhas de distribuição. Na Europa e Japão o uso deste já é bastante significativo, mas no Brasil ele ainda é alvo de pesquisa, principalmente, para avaliação da sua soldabilidade [3].

Durante os processos de soldagem, muitas são as alterações metalúrgicas sofridas pelos materiais quando submetidos a um ciclo térmico de soldagem, destacando-se o surgimento de tensões residuais [4]. O surgimento de tensões residuais após o processo de soldagem exerce uma considerável influência sobre as propriedades mecânicas das juntas soldadas e seu controle 
permite evitar possíveis falhas da estrutura soldada [5].

Muitos mecanismos relevantes de degradação podem ser acelerados pela presença de tensões residuais. Tensões residuais trativas, por exemplo, podem contribuir para o desenvolvimento de trincas de fadiga. Similarmente, a corrosão sob tensão pode ocorrer em soldas se a soma da tensão aplicada e a tensão residual excederem um valor limite [6]. Nesse sentido, o grande desafio é, portanto, manter a alta resistência sem prejuízo da tenacidade devido a Zona Termicamente Afetada (ZTA), principalmente considerando-se o processo de corrosão e demais processos de fragilização que são dependentes, também, dos níveis de tensões residuais oriundas dos processos de soldagem [7].

Sendo assim, o objetivo desse trabalho foi avaliar os níveis de tensões residuais, através da difração de raios- $x$, em juntas soldadas do aço API 5L X80 utilizando os processos de soldagem ao arco elétrico com eletrodo revestido (SMAW) e com eletrodo de tungstênio com proteção gasosa (GTAW).

\section{Materiais e Métodos}

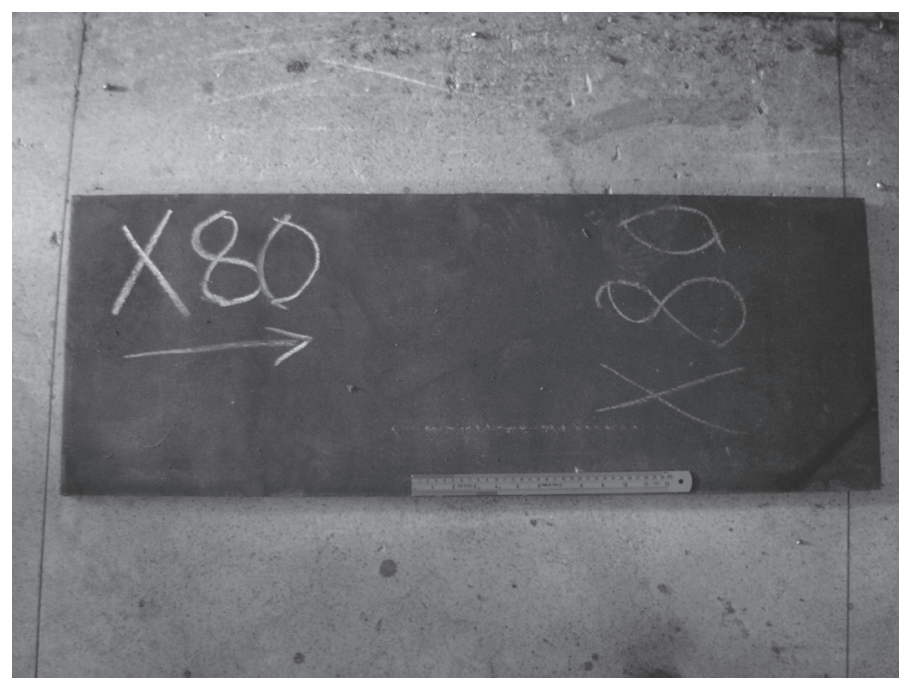

(a)
Neste trabalho utilizou-se uma chapa do aço API 5L X80, conforme Figura 1a, de $120 \mathrm{~mm}$ x $360 \mathrm{~mm}$ e $17 \mathrm{~mm}$ de espessura, chanfrada com ângulo de $60^{\circ}$ (Figura 1b). Os processos de soldagem utilizados para o passe de raiz foram o processo SMAW com eletrodo AWS E 6010 de 3,25 mm de diâmetro, e o processo GTAW com arame AWS ER70S-3 de $2 \mathrm{~mm}$ de diâmetro. $\mathrm{O}$ gás de proteção utilizado no processo GTAW foi o Argônio. A Tabela 1 mostra a composição química do aço empregado e a Tabela 2 indica a composição química dos consumíveis utilizados. Foram executados 8 passes de soldagem conforme ilustrado na Figura 1c. Na Tabela 3 são indicados os consumíveis empregados, bem como os processos de soldagem na execução de cada passe. A temperatura de interpasse foi de $175^{\circ} \mathrm{C}$ e as soldas foram executadas com as chapas sem restrição. $\mathrm{O}$ espaçamento entre as juntas foi a medida do diâmetro do eletrodo empregado. $\mathrm{O}$ rendimento térmico da fonte de energia adotado para o processo SMAW foi de 0,8 e para o processo GTAW foi de 0,65 de acordo com Machado [8]. Nas Tabelas 4, 5 e 6 são apresentados os parâmetros de soldagem das três juntas.

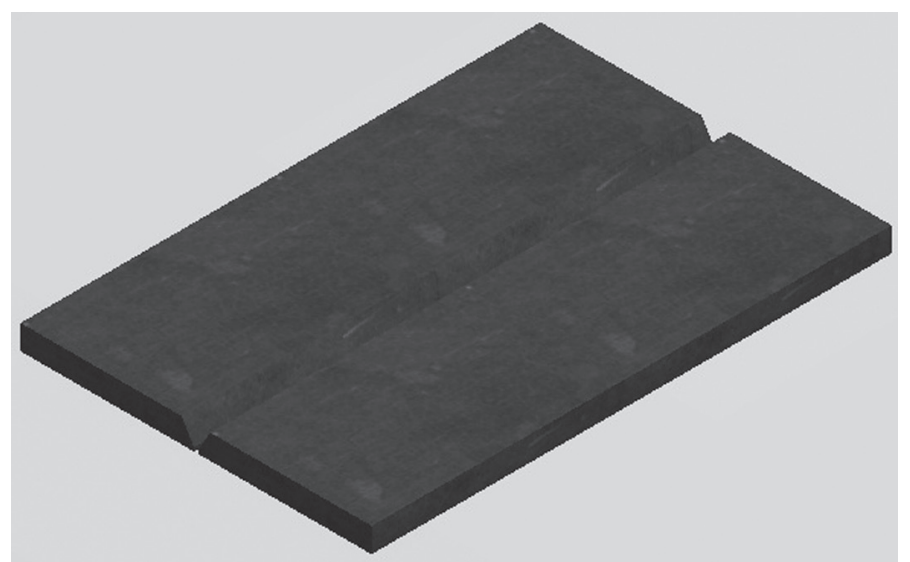

(b)

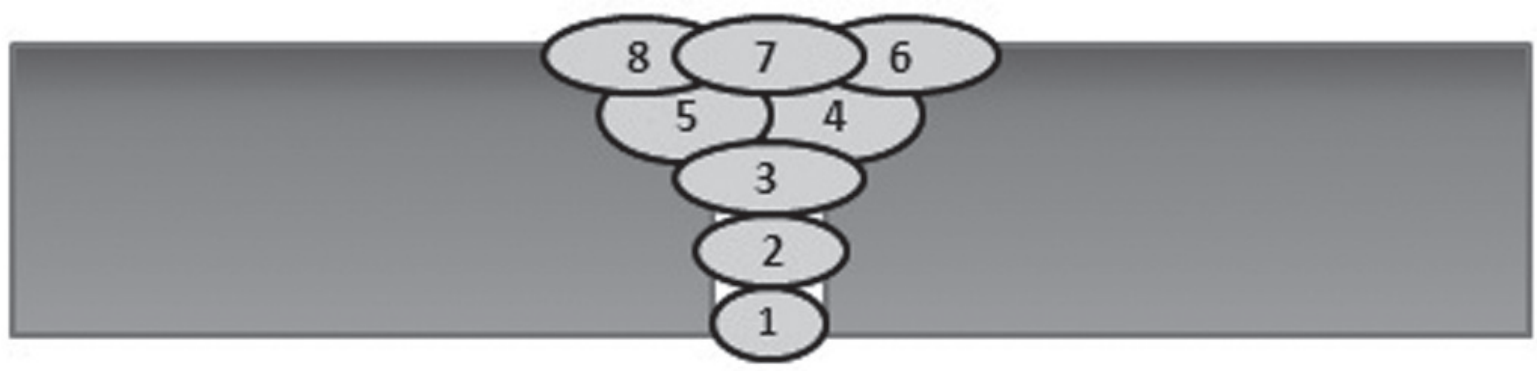

(c)

Figura 1. Junta a ser soldada. a) Chapa de aço API 5L X80 empregada, b) Representação da chapa cortada e chanfrada e c) Número de passes e sequencia de soldagem empregada. 
Tabela 1. Composição química do aço API 5L X80 fornecida pelo fabricante.

\begin{tabular}{|c|c|c|c|c|c|c|c|c|c|c|}
\hline \multicolumn{10}{|c|}{ Porcentagem (\%) em peso } \\
\hline $\mathrm{C}$ & $\mathrm{Mn}$ & $\mathrm{Si}$ & $\mathrm{P}$ & $\mathrm{S}$ & $\mathrm{Ni}$ & $\mathrm{Mo}$ & $\mathrm{Al}$ & $\mathrm{Cr}$ & $\mathrm{V}$ & $\mathrm{Cu}$ \\
\hline 0,084 & 1,61 & 0,23 & 0,011 & 0,011 & 0,011 & 0,17 & 0,035 & 0,135 & 0,015 & 0,029 \\
\hline
\end{tabular}

Tabela 2. Composição química dos consumíveis empregados.

\begin{tabular}{|c|c|c|c|c|c|c|c|c|c|}
\hline \multirow{2}{*}{ CONSUMÍVEL } & \multicolumn{9}{|c|}{ Porcentagem em peso (\%) } \\
\cline { 2 - 11 } & $\mathrm{C}$ & $\mathrm{Mn}$ & $\mathrm{Si}$ & $\mathrm{P}$ & $\mathrm{S}$ & $\mathrm{Ni}$ & $\mathrm{Mo}$ & $\mathrm{Cr}$ & $\mathrm{V}$ \\
\hline E6010 & 0,09 & 0,35 & 0,15 & 0,010 & 0,010 & - & - & - & - \\
\hline ER70S-3 & 0,10 & 1,10 & 0,60 & - & - & - & - & - & - \\
\hline E8010 & 0,07 & 0,60 & 0,13 & - & - & 0,70 & 0,30 & - & - \\
\hline E8018-G & 0,06 & 1,10 & 0,40 & - & - & 1,65 & - & - & - \\
\hline E9010 & 0,10 & 0,90 & 0,20 & 0,019 & 0,009 & 0,80 & 0,50 & 0,015 & 0,008 \\
\hline E9018-G & 0,05 & 1,10 & 0,50 & - & - & 1,60 & 0,20 & - & - \\
\hline E91T8-K8 & 0,06 & 1,20 & 0,40 & - & - & 0,85 & 015 & - & - \\
\hline
\end{tabular}

Tabela 3. Consumíveis empregados nas diferentes condições de soldagem.

\begin{tabular}{|c|c|c|c|c|c|}
\hline \multicolumn{7}{|c|}{ Consumíveis empregados } \\
\hline Sequência & Passe de Raiz & $\begin{array}{c}\text { Passe } \\
\text { Quente }\end{array}$ & $\begin{array}{c}\text { Passe de } \\
\text { Enchimento }\end{array}$ & Passe de Acabamento & Processos \\
\hline T1.0 & ER70S -3 - GTAW & E8010 & E8018-G & E8018-G & GTAW+SMAW \\
\hline T2.0 & ER70S -3 - GTAW & E9010 & E9018-G & E9018-G & GTAW+SMAW \\
\hline E1.0 & E6010 - SMAW & E8010 & E8018-G & E8018-G & SMAW \\
\hline
\end{tabular}

Tabela 4. Parâmetros de soldagem para a condição de soldagem T1.0.

\begin{tabular}{|c|c|c|c|c|c|}
\hline \multicolumn{2}{|c|}{ Passes } & $\mathrm{I}(\mathrm{A})$ & $\mathrm{V}(\mathrm{V})$ & $\mathrm{H}(\mathrm{kJ} / \mathrm{mm})$ & $\mathrm{v}(\mathrm{mm} / \mathrm{s})$ \\
\hline 1 & Raiz & 152,4 & 12,04 & 0,9 & 1,25 \\
\hline 2 & Quente & 68,8 & 33,38 & 1,2 & 1,50 \\
\hline 3 & Enchimento & 110,9 & 20,88 & 1,6 & 1,15 \\
\hline 4 & Enchimento & 130,6 & 20,11 & 0,9 & 2,27 \\
\hline 5 & Enchimento & 130,9 & 20,52 & 1,2 & 1,73 \\
\hline 6 & Acabamento & 130,8 & 20,85 & 1,0 & 2,12 \\
\hline 7 & Acabamento & 130,8 & 20,16 & 0,9 & 2,37 \\
\hline 8 & Acabamento & 130,7 & 19,73 & 1,0 & 2,09 \\
\hline
\end{tabular}

Tabela 5. Parâmetros de soldagem para a condição de soldagem T2.0.

\begin{tabular}{|c|c|c|c|c|c|}
\hline \multicolumn{2}{|c|}{ Passes } & $\mathrm{I}(\mathrm{A})$ & $\mathrm{V}(\mathrm{V})$ & $\mathrm{H}(\mathrm{kJ} / \mathrm{mm})$ & $\mathrm{v}(\mathrm{mm} / \mathrm{s})$ \\
\hline 1 & Raiz & 156,6 & 12,56 & 1,3 & 0,96 \\
\hline 2 & Quente & 86,5 & 34,56 & 1,5 & 1,58 \\
\hline 3 & Enchimento & 113,4 & 23,49 & 1,7 & 1,21 \\
\hline 4 & Enchimento & 116,6 & 21,68 & 1,1 & 1,87 \\
\hline 5 & Enchimento & 116,5 & 21,74 & 0,9 & 2,12 \\
\hline 6 & Acabamento & 116,5 & 21,42 & 1,1 & 1,84 \\
\hline 7 & Acabamento & 116,7 & 22,29 & 0,8 & 2,39 \\
\hline 8 & Acabamento & 118,5 & 21,85 & 0,8 & 2,62 \\
\hline
\end{tabular}


Tabela 6. Parâmetros de soldagem para a condição de soldagem E1.0.

\begin{tabular}{|c|c|c|c|c|c|}
\hline \multicolumn{2}{|c|}{ Passes } & $\mathrm{I}(\mathrm{A})$ & $\mathrm{V}(\mathrm{V})$ & $\mathrm{H}(\mathrm{kJ} / \mathrm{mm})$ & $\mathrm{v}(\mathrm{mm} / \mathrm{s})$ \\
\hline 1 & Raiz & 54,2 & 35,76 & 1,5 & 1,00 \\
\hline 2 & Quente & 81,8 & 33,17 & 1,4 & 1,54 \\
\hline 3 & Enchimento & 160,5 & 21,78 & 1,5 & 1,78 \\
\hline 4 & Enchimento & 165,5 & 21,20 & 1,0 & 2,72 \\
\hline 5 & Enchimento & 165,3 & 22,19 & 1,0 & 2,74 \\
\hline 6 & Acabamento & 165,1 & 22,40 & 1,2 & 2,50 \\
\hline 7 & Acabamento & 165,4 & 22,19 & 1,0 & 2,89 \\
\hline 8 & Acabamento & 165,3 & 22,52 & 0,9 & 3,14 \\
\hline
\end{tabular}

\subsection{Ataque Eletrolítico}

Antes de serem realizadas as análises de tensão residual por difração de raios-x as juntas soldadas foram submetidas a um ataque eletrolítico para a remoção de camada de óxidos de modo a não interferir nas análises posteriores. A solução empregada para a realização do ataque foi ácido clorídrico $(\mathrm{HCl})$ com $10 \%$ de concentração numa densidade de corrente de $0,25 \mathrm{~A} / \mathrm{cm}^{2}$ por um tempo de 20 minutos, conforme sugerido por Costa et al. [9]. Foi empregado um aço inoxidável ferrítico como cátodo. Utilizou-se uma fonte retificadora AC-CC (TECTROL - Modelo TCA-30V, 30 $0^{\mathrm{a}}$ OBR1A) para fornecimento da corrente desejada de modo a se obter a densidade de corrente citada acima... A Figura 2 ilustra a junta soldada com a respectiva célula eletrolítica.

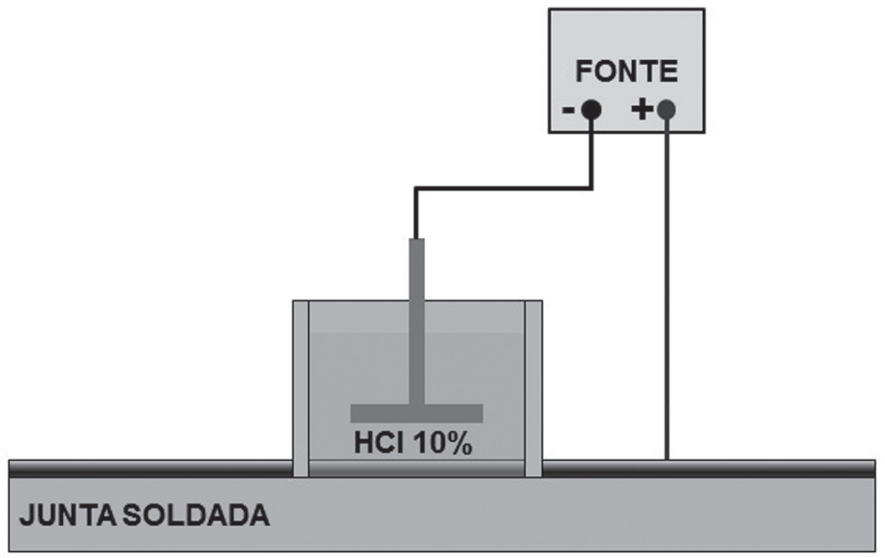

Figura 2. Ilustração da junta soldada com a célula para ataque eletrolítico.

\subsection{Análise das Tensões Residuais}

O método de difração de raios-x é uma técnica bem estabelecida para medição de tensões residuais [10]. As medidas de tensões residuais são determinadas de acordo com a Equação 1.

$$
\sigma_{\phi}=\frac{E}{(1+v) \operatorname{sen}^{2} \psi}\left(\frac{d_{\phi \psi}-d_{0}}{d_{0}}\right)
$$

Onde $\sigma_{\Phi}$ é a tensão residual superficial; $d_{\phi_{\psi}}$ é o espaçamento interplanar definido pelos ângulos $\Phi$ e $\psi$, obtida a partir da posição do pico de difração para um dado plano do retículo cristalino $(h k l) ; d_{0}$ é o espaçamento interplanar livre de tensão do plano $(h k l)$ do retículo cristalino, e $E$ e $v$ são o módulo de elasticidade e coeficiente de Poisson, respectivamente.

A relação linear na Equação 1 para tensão residual implica que a plotagem da deformação do retículo cristalino versus $\operatorname{sen}^{2} \Psi$ será uma reta, a qual o gradiente é função de $\sigma_{\phi}, E$ e $v$. O valor de $\sigma_{\Phi}$ pode ser calculado a partir do gradiente da linha reta para vários ângulos de inclinação $\Psi$. Usando a Lei de Bragg, a Equação 1 pode ser reescrita como:

$$
\sigma_{\phi}=\frac{E}{(1+v)} \frac{\cot g \theta \Delta \theta}{\operatorname{sen}^{2} \psi}
$$

Para análise das tensões residuais foi utilizado um difratômetro portátil - Portable stress analyser STRESSRAD (RADICON Ltd. Scientific Instruments) juntamente com o software de análise do equipamento - Stress. Uma vez que o material utilizado neste trabalho possui uma estrutura ferrítica, a análise foi feita nos planos (211) com o emprego de um comprimento de onda de $\lambda$ $=2,2911 \AA$. Este comprimento de onda é produzido por um tubo anódico de Cromo [11]. O método empregado foi o $\operatorname{sen}^{2} \psi$, com medidas realizadas para $\psi=0^{\circ}, 20^{\circ}, 30^{\circ}, 35^{\circ}, 45^{\circ}$.

Foram realizadas análises em três regiões distintas (A, B e C) de todas as juntas, tanto na região inferior da junta (Passe de raiz) quanto na região superior (Acabamento). A Figura 3 ilustra a disposição dos pontos analisados nas juntas. Ao longo de cada região foram analisados 31 pontos espaçados de $2 \mathrm{~mm}$. A origem das medidas foi colocada como sendo o centro da junta, sendo analisados 15 pontos à sua direita e 15 pontos à sua esquerda.

\section{Resultados e discussões}

\subsection{Análise dos resultados da parte superior das juntas}

A partir dos dados obtidos por difração de raios-x foi possível plotar os resultados de tensões residuais para as juntas analisadas. Os experimentos foram realizados inicialmente na parte superior da junta e posteriormente na parte inferior da junta. As Figuras 4 a 6 mostram a distribuição de tensões residuais longitudinais e transversais no Metal de Solda (MS), e no Metal de Base (MB), nas partes superiores das respectivas juntas estudadas. 


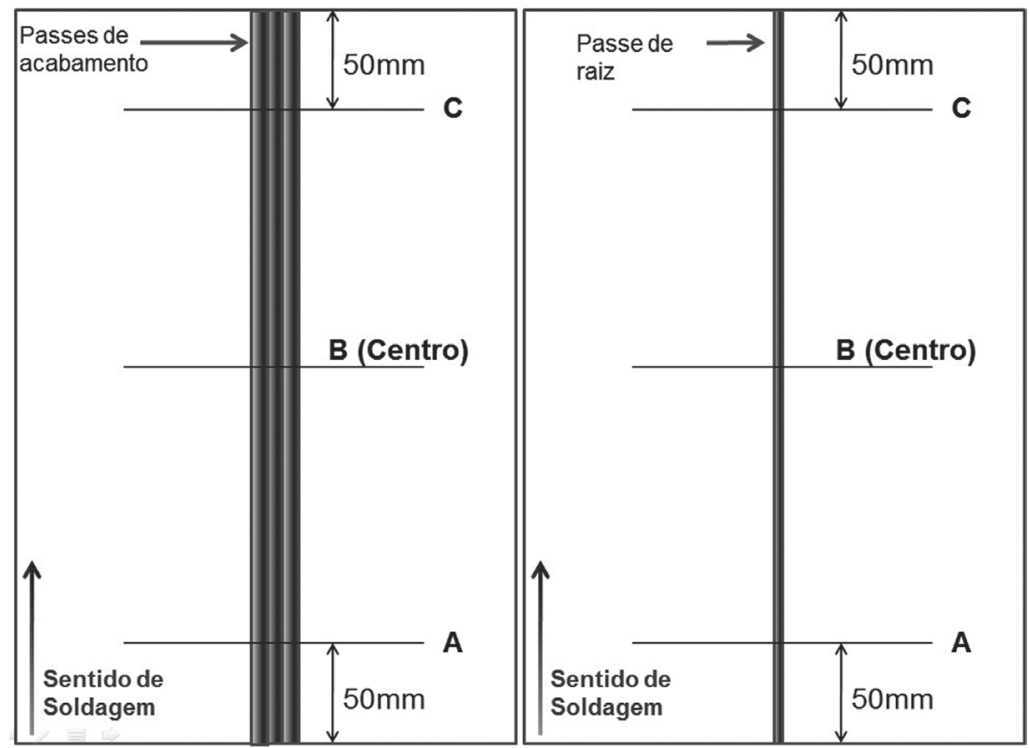

Figura 3. Regiões onde foram analisadas as tensões residuais.

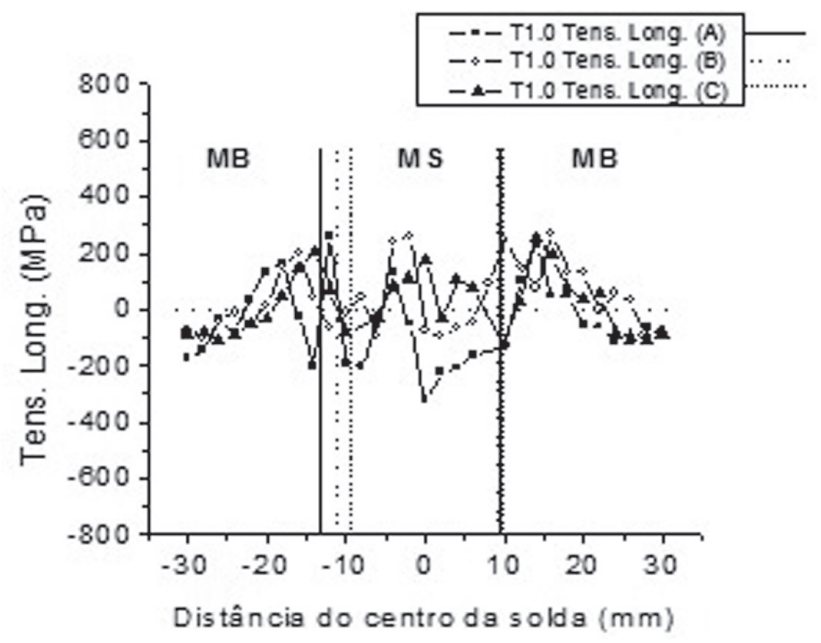

(a)

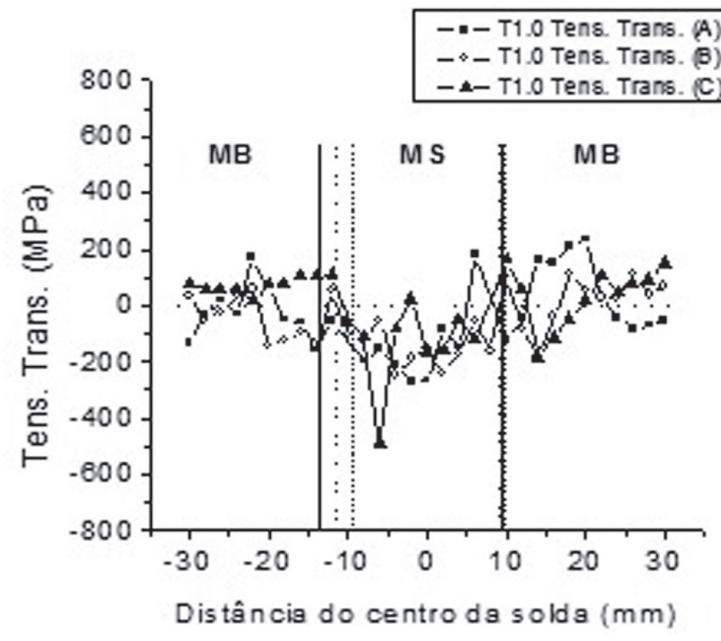

(b)

Figura 4. Distribuição de tensões residuais ao longo da região superior da junta T1.0; (a) tensões longitudinais (b) tensões transversais.

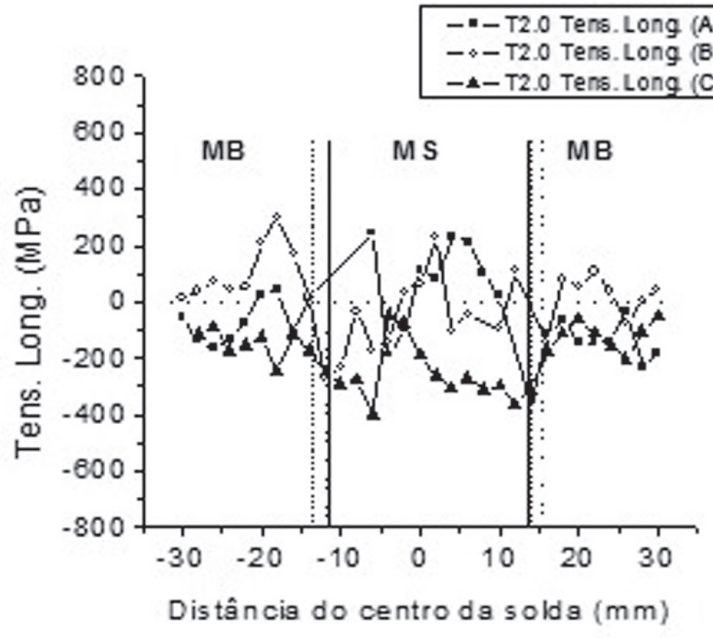

(a)

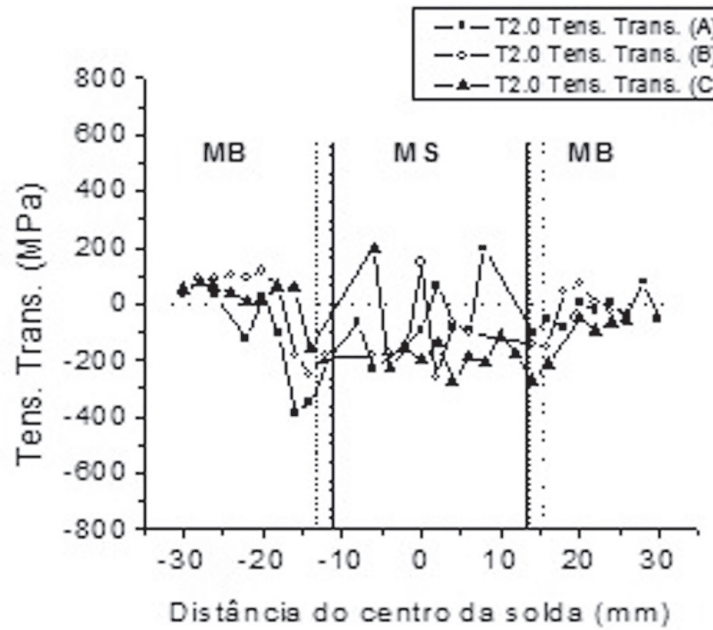

(b)

Figura 5. Distribuição de tensões residuais ao longo da região superior da junta T2.0; (a) tensões longitudinais (b) tensões transversais. 


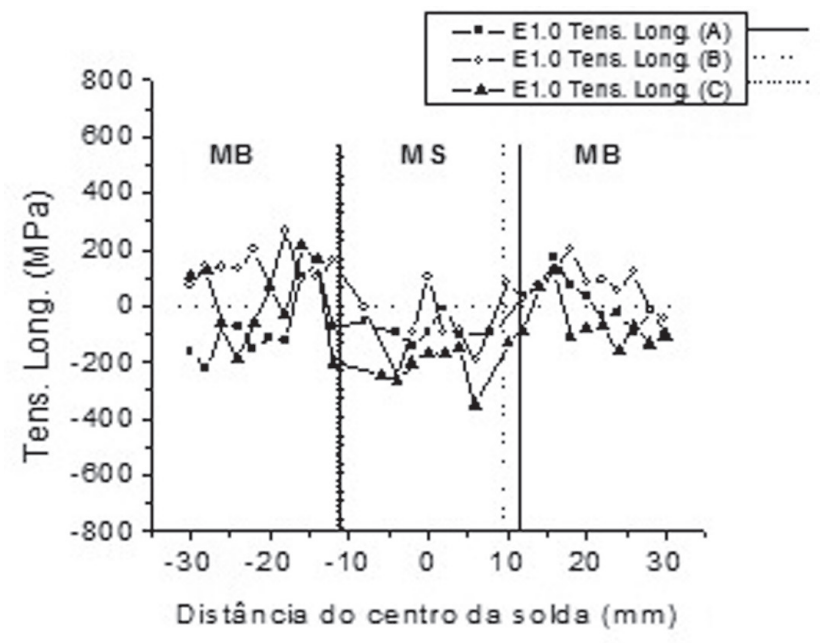

(a)

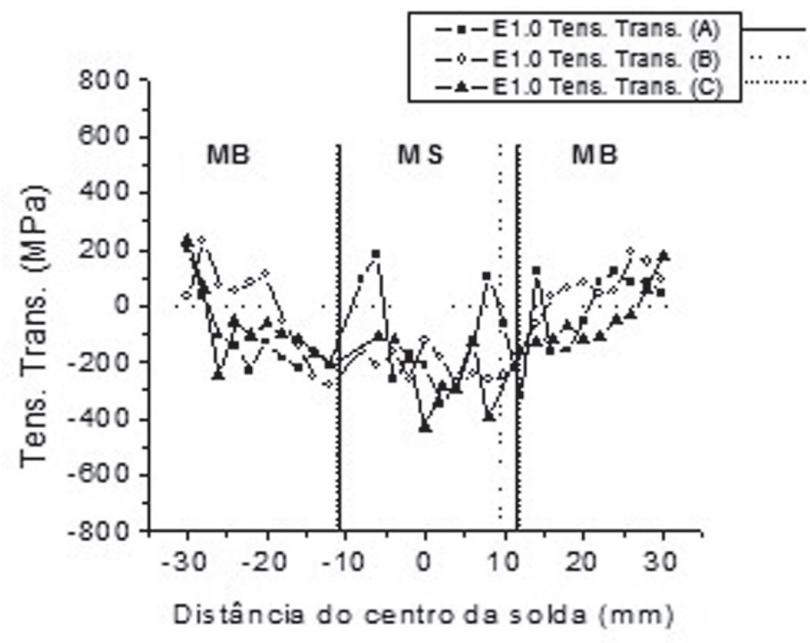

(b)

Figura 6. Distribuição de tensões residuais ao longo da região superior da junta E1.0; (a) tensões longitudinais (b) tensões transversais. Na Figura 4, avaliando-se a região superior da junta T1.0 é possível verificar que os maiores valores de tensões residuais trativas

localizam-se, principalmente nas regiões próximas ao $\mathrm{MS}$, ou seja, na provável região da ZTA. O comportamento das tensões residuais longitudinais e transversais apresentou uma regularidade ao longo de toda a junta, ou seja, nas regiões A, B e C. As tensões residuais longitudinais são trativas nas proximidades do centro de MS e na região do MB imediatamente após a zona de ligação entre o MS e o MB.

Considerando-se, agora, a região superior da junta T2.0 (Figura 5) é possível verificar que a região da zona fundida não apresentou um comportamento tão bem definido quanto as demais condições, principalmente quando se avalia as tensões residuais longitudinais. Nesta junta é verificado um menor nível de tensões residuais, principalmente na região próxima à ZTA.

Avaliando-se a região superior da junta E1.0 (Figura 6) é possível verificar que os perfis das tensões residuais longitudinais e transversais foram similares no que diz respeito ao perfil das curvas nas três regiões de análise das tensões residuais. Diferentemente das outras duas condições de soldagem (juntas T1.0 e T2.0), os maiores níveis de tensões residuais transversais são localizados em pontos mais distantes da zona de ligação entre o MS e o MB.

As regiões superiores das juntas que foram submetidas à análise de tensões residuais são compostas dos passes de acabamento e do MB. Considerações podem ser realizadas em função do nível de tensões residuais transversais considerandose os parâmetros de soldagem empregados. As juntas T1.0, T2.0 e E1.0 foram soldadas com aportes térmicos médios nos passes de acabamento de aproximadamente $0,96 \mathrm{~kJ} / \mathrm{mm}, 0,90 \mathrm{~kJ} / \mathrm{mm}$ e $1,03 \mathrm{~kJ} / \mathrm{mm}$, respectivamente. As correntes médias empregadas nos passes de acabamento para as juntas T1.0, T2.0 e E1.0 foram de 130,7 A, 117,2 A e 165,2 A, respectivamente. Conforme mostrado na Tabela 3, as juntas T1.0 e E1.0, apresentaram os mesmos consumíveis nos passes de acabamento. Logo, pode ser verificado que, para o presente caso, o emprego de um maior aporte térmico acarretou um uma intensidade ligeiramente maior de tensões residuais compressivas, conforme pode ser observado na junta E1.0. Para o presente trabalho, considerandose principalmente as juntas T1.0 e T2.0, as pequenas diferenças nos aportes térmicos não alteraram de forma substancial a intensidade das tensões residuais transversais, entretanto, conforme já mencionado, o maior aumento deste parâmetro utilizado na junta E1.0 intensificou as tensões residuais compressivas ao longo da junta. Sabe-se que o emprego de um maior aporte térmico pode gerar um maior nível de tensões residuais trativas [6,12], entretanto, deve-se salientar que os casos apresentados na literatura são muitas vezes decorrentes de diferentes processos de soldagem, juntamente com diferentes condições e geometrias de juntas soldadas. Gao et al. [13] encontraram resultados semelhantes aos aqui encontrados em juntas soldadas do aço HSLA-100, onde as tensões residuais foram sempre compressivas sobre a superfície da solda, e nas suas proximidades, tornando-se gradualmente trativas a medida que a distância a partir da solda aumentava, sendo esse fenômeno atribuído ao efeito de transformações de fase no aço, uma vez que a expansão volumétrica associada à transformação da austenita para martensita/bainita podem aumentar o nível de tensões compressivas.

\subsection{Análise dos resultados da parte inferior das juntas}

As Figuras 7 a 9 mostram a distribuição de tensões residuais longitudinais e transversais no Metal de Solda (MS), e no Metal de Base (MB), nas partes e inferiores das respectivas juntas estudadas. 

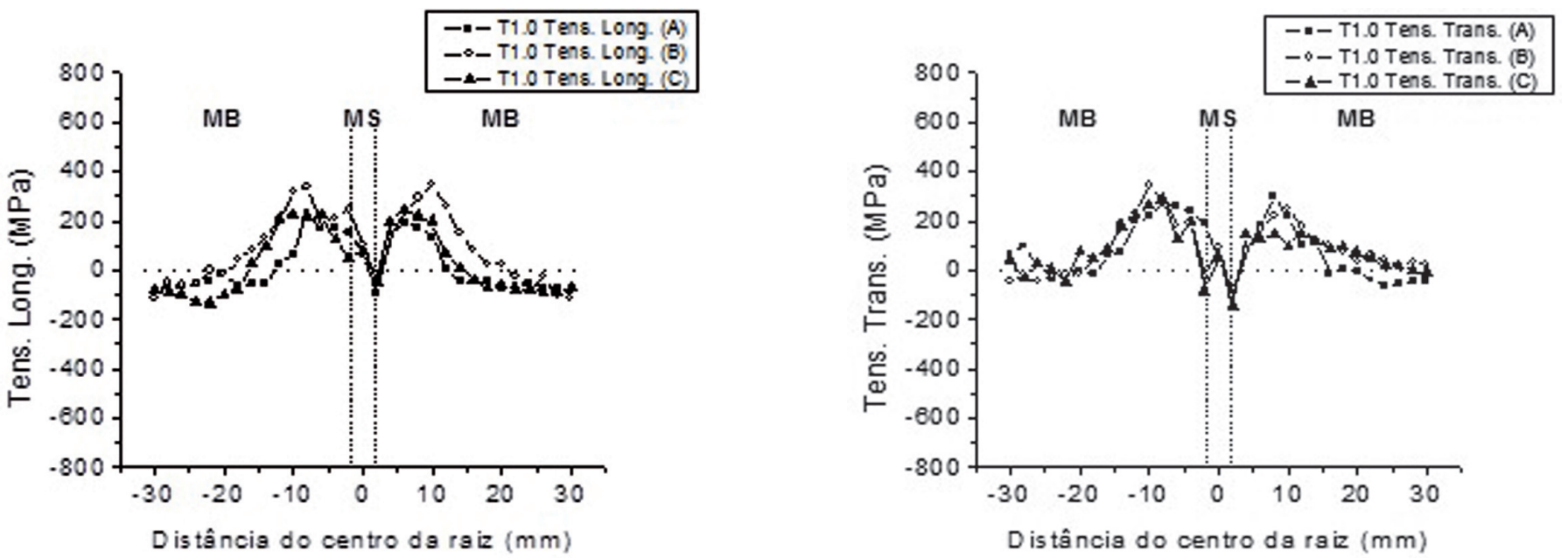

Figura 7. Distribuição de tensões residuais ao longo da região inferior da junta T1.0; (a) tensões longitudinais (b) tensões transversais.

(a)

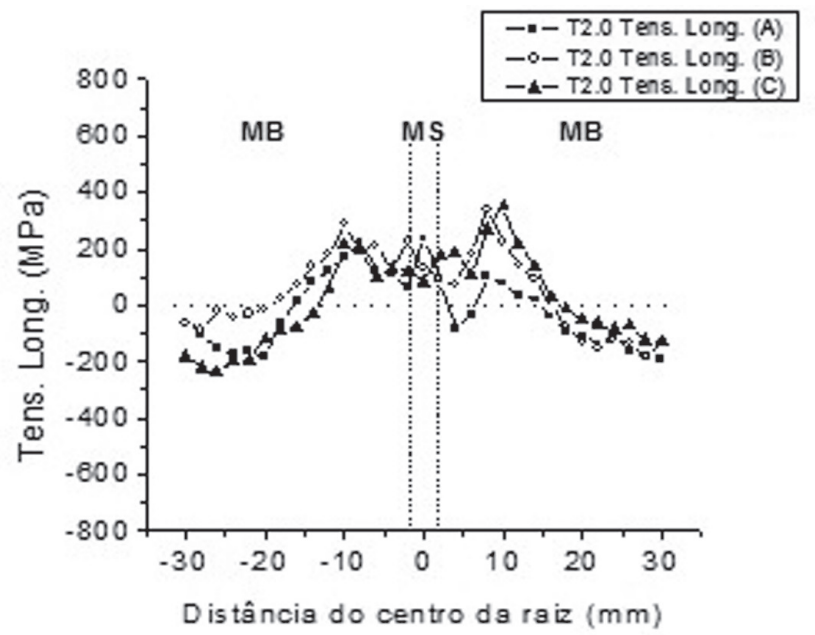

(b)

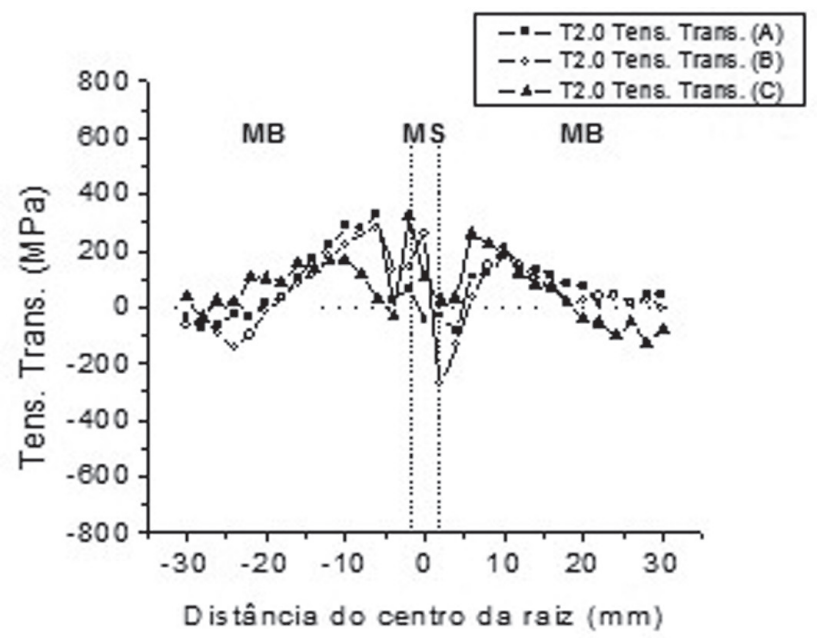

Figura 8. Distribuição de tensões residuais ao longo da região inferior da junta T2.0; (a) tensões longitudinais (b) tensões transversais.

(a)

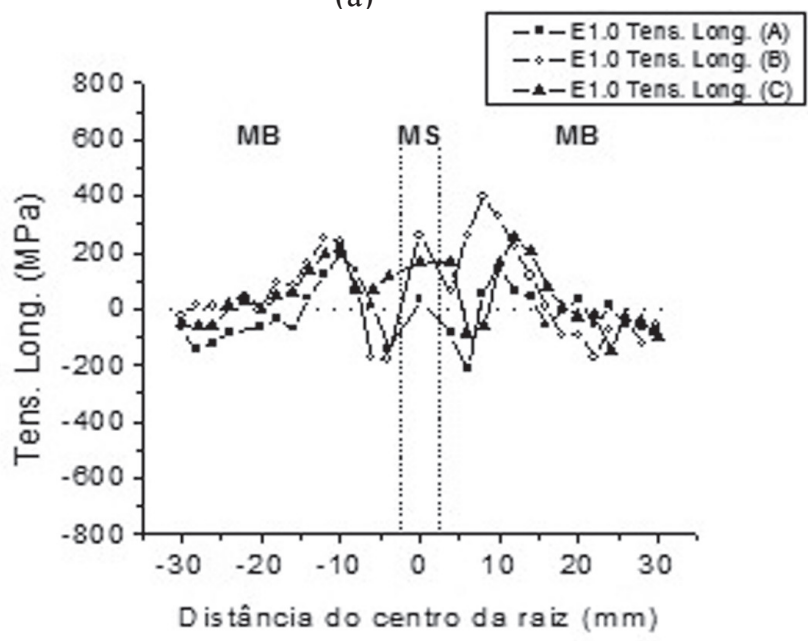

(b)

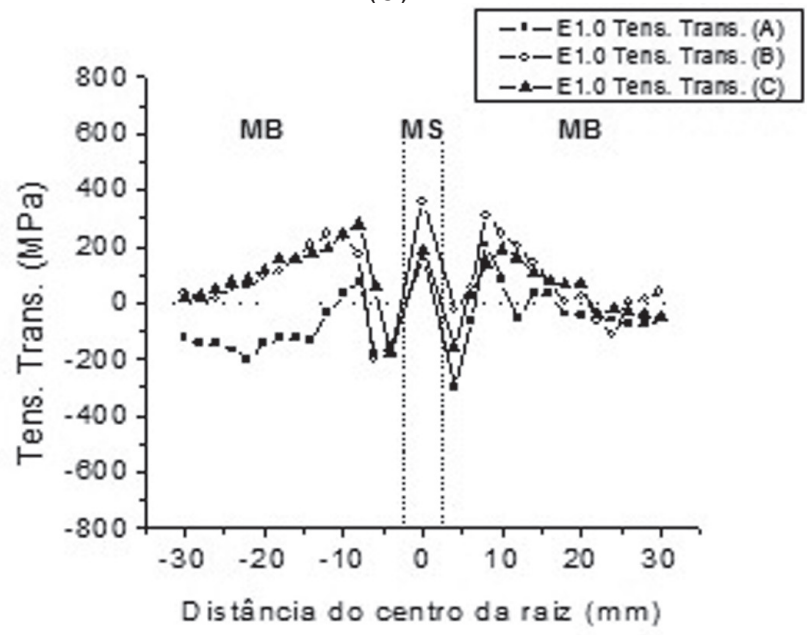

Figura 9. Distribuição de tensões residuais ao longo da região inferior da junta E1.0; (a) tensões longitudinais (b) tensões transversais. 
Diferentemente da região superior da chapa, verifica-se que os perfis de tensões residuais ao longo da junta apresentam uma melhor regularidade, pois a análise se dá praticamente apenas na região do $\mathrm{MB}$, tendo em vista que a região do passe de raiz apresenta menores dimensões em relação à região dos passes de acabamento.

Devido à importância da execução do passe de raiz e considerando que este estará em contato direto com contaminantes como $\mathrm{H}_{2} \mathrm{~S}$, atenção especial será dada as tensões residuais transversais, tendo em vista que elas são consideradas as mais importantes em fenômenos de fragilização por hidrogênio e corrosão-sob-tensão [14].

Os passes de raiz das juntas T1.0, T2.0 e E1.0 foram soldados pelos processos, GTAW, GTAW e SMAW respectivamente. Os aportes térmicos médios entre os passes de raiz e passes quente das juntas foram de $1,05 \mathrm{~kJ} / \mathrm{mm}, 1,40 \mathrm{~kJ} / \mathrm{mm}$ e $1,45 \mathrm{~kJ} / \mathrm{mm}$ e as correntes empregadas foram 152,4 A, 156,6 A e 54,2 A.

Comparando-se as Figuras 7a, 8a e 9a é possível verificar que o emprego de maiores aportes térmicos implica em maiores níveis de tensões residuais transversais trativas no MS. As juntas T1.0 e T2.0 foram executadas com mesmos processos de soldagem na execução dos passes de raiz (GTAW). Devido ao

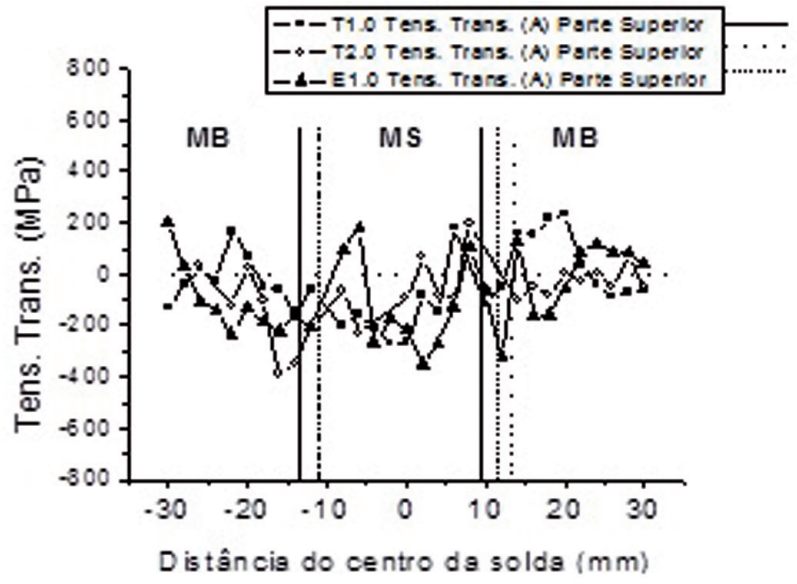

(a) fato do passe de raiz da junta T1.0 ter sido realizado com aporte térmico de $1,05 \mathrm{~kJ} / \mathrm{mm}$ e a junta $\mathrm{T} 2.0 \mathrm{de} 1,40 \mathrm{~kJ} / \mathrm{mm}$, maiores níveis de tensões residuais transversais foram apresentados pela junta T2.0. Como o passe da raiz da junta E1.0 foi realizado pelo processo SMAW com um aporte térmico ligeiramente maior $(1,45 \mathrm{~kJ} / \mathrm{mm})$, maiores níveis de tensões residuais transversais foram apresentados em relação às juntas T1.0 e T2.0. Nas regiões adjacentes ao MS - ZTA e MB - os níveis de tensões residuais foram semelhantes para as três condições de soldagem empregadas. Ou seja, a diferença de aportes térmicos não foi suficiente para promover variações significantes nas magnitudes das tensões residuais nas regiões mais afastadas da junta soldada, embora tenha sido suficiente para promover variações nos níveis de tensões residuais na região do MS.

\subsection{Comparação das análises dos resultados}

As Figuras 10, 11, e 12, apresenta uma comparação entre os níveis de tensões residuais transversais nas regiões em estudo das juntas soldadas (A, B e C). Nestas Figuras, pode-se perceber a influência do procedimento de soldagem empregado sobre os níveis de tensões residuais em cada região.

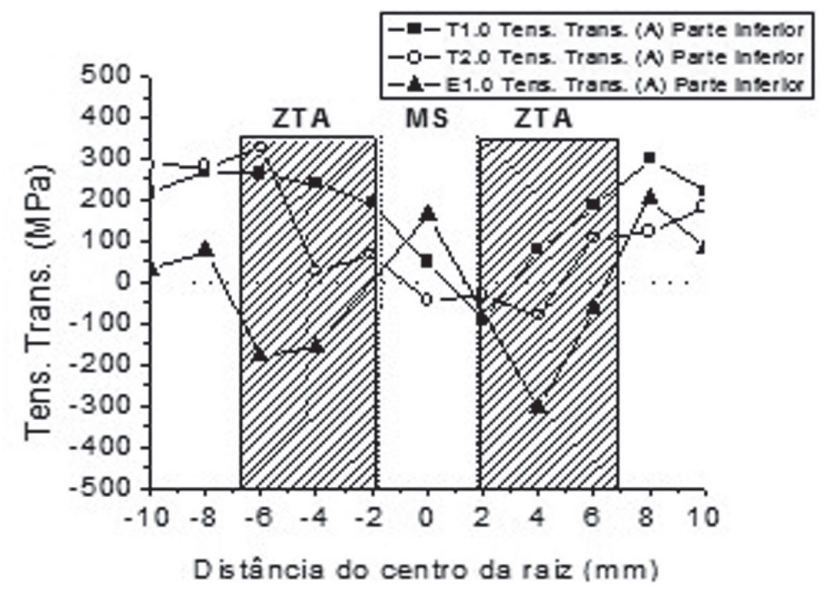

(b)

Figura 10. Distribuição de tensões residuais transversais nas juntas soldadas; (a) Região A superior; (b) Região A inferior.

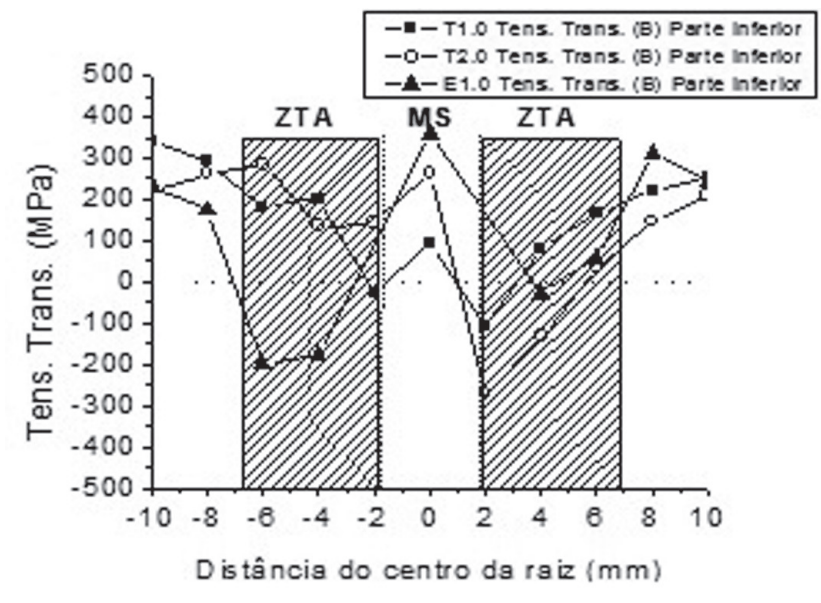

(a)

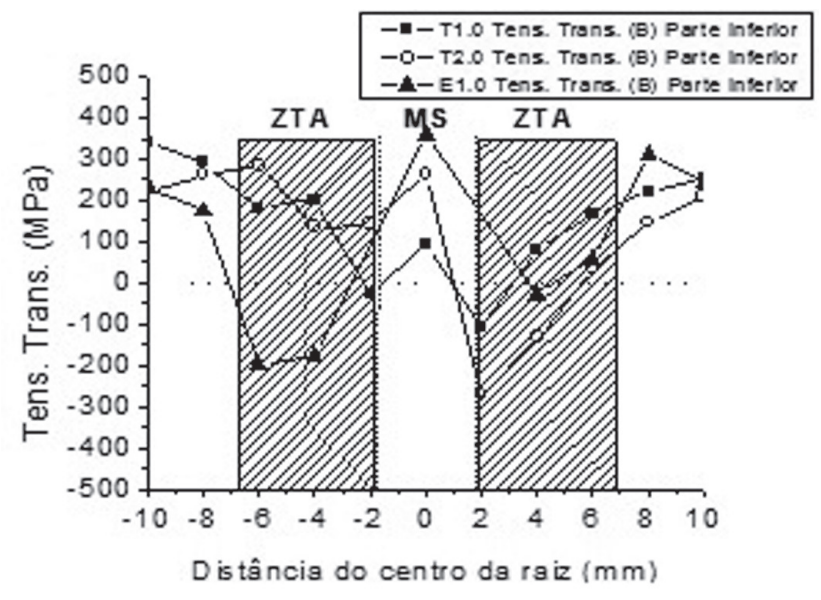

(b)

Figura 11. Distribuição de tensões residuais transversais nas juntas soldadas; (a) Região B superior; (b) Região B inferior. 


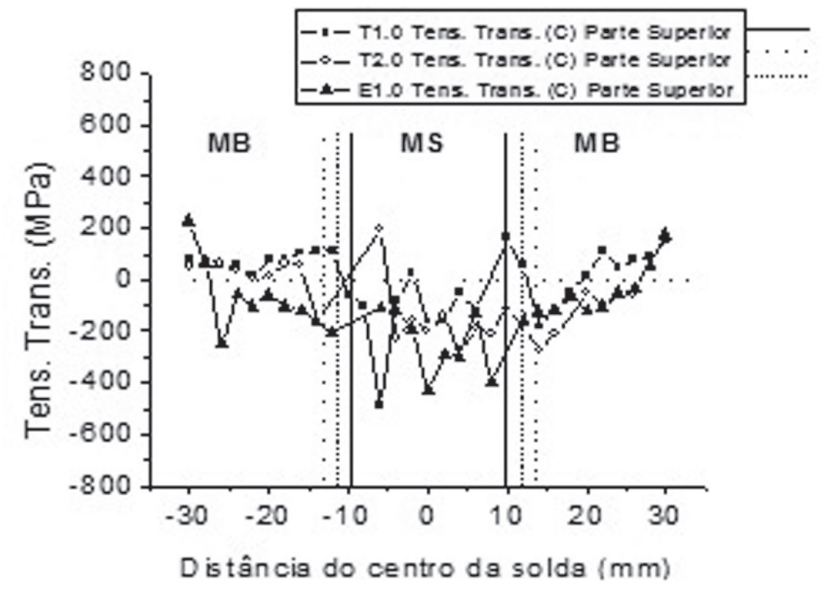

(a)

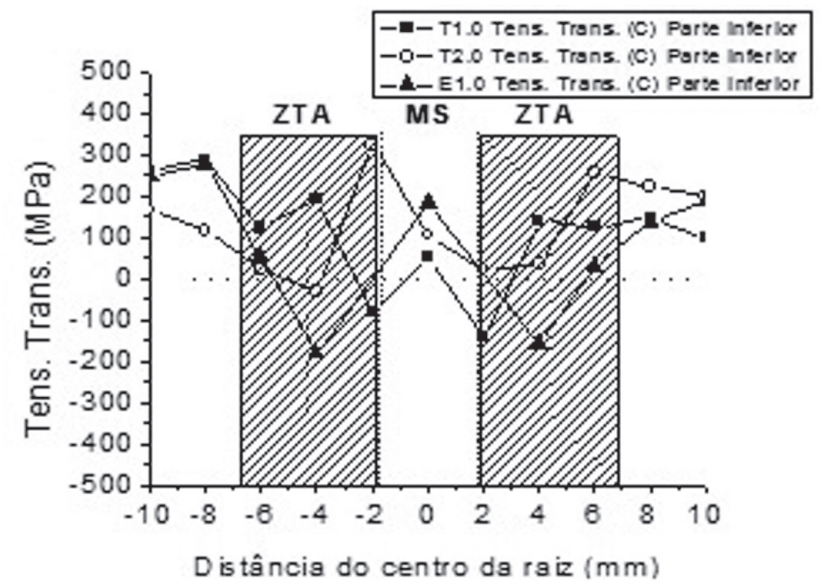

(b)

Figura 12. Distribuição de tensões residuais transversais nas juntas soldadas; (a) Região C superior; (b) Região C inferior.

Nas Figuras apresentadas pode-se perceber de forma clara, conforme já mencionado em discussão anterior, que nas regiões superiores das juntas soldadas quanto maior o aporte térmico empregado, mais compressivas foram as tensões residuais transversais no MS. Na região superior, considerando o MS, os valores médios das tensões residuais transversais entre as três regiões analisadas foram $-112,8 \mathrm{MPa}$ para a junta T1.0, $-115,2$ MPa para a junta T2.0 e $-188,0 \mathrm{MPa}$ para a junta E1.0. Nas regiões inferiores das juntas soldadas, quanto maior o aporte térmico empregado, mais trativas foram as tensões residuais no MS. Consequentemente, os valores médios das tensões residuais transversais entre as três regiões analisadas foram $64,6 \mathrm{MPa}$ para a junta T1.0, 108,3 MPa para a junta T2.0 e 235 Mpa para a junta E1.0.

Sabendo-se que as tensões residuais transversais desempenham importante papel na susceptibilidade à trincamento em condições de serviço, em ambientes ricos em $\mathrm{H}_{2} \mathrm{~S}$, por exemplo, as tensões residuais junto ao "pé" do passe de raiz precisam ser analisadas, pois estas regiões são regiões preferenciais para o surgimento de trincamento em serviço [15]. Sendo assim, foi verificado que o emprego de maiores aportes térmicos junto ao passe de raiz apesar de aumentar as tensões residuais trativas no metal de solda conduz a maiores níveis de tensões residuais compressivas na ZTA junto ao "pé" do passe. Como normalmente esta é a região mais crítica da junta soldada tendo em vista a maior granulometria e a maior possibilidade de regiões martensíticas, isto pode diminuir a susceptibilidade ao trincamento em serviço. Os valores médios das tensões residuais transversais na região junto ao "pé" do passe de raiz, ou seja, na ZTA, foram 94,9 MPa para a junta T1.0, 68,3 MPa para a junta T2.0 e -109,5 MPa para a junta E1.0.

\section{Conclusões}

No presente trabalho, foi possível determinar os níveis de tensões residuais longitudinais e transversais decorrentes de processos de soldagem em juntas soldadas de um aço API 5L X80. Diante dos resultados obtidos, pode-se concluir que:
- Na região superior das juntas soldadas, as tensões residuais transversais foram 59\% mais compressivas com maiores aporte térmicos;

- No caso da região superior das juntas soldadas, menores aportes térmicos implicaram em picos de tensões residuais longitudinais trativas no MS que foram amenizados com o emprego de maiores aportes térmicos;

- Na região inferior das juntas soldadas, os valores de tensões residuais transversais foram até 3,6 vezes mais trativas quando empregou-se maiores aportes térmicos;

- Na ZTA da região inferior os níveis de tensões foram mais compressivos com o emprego de maiores aportes térmicos.

\section{Agradecimentos}

Os autores agradecem aos Laboratórios de Soldagem (LABSOL-UFCG), Laboratório de Engenharia Eletroquímica (LEEq-UFCG) e a CAPES pelo auxílio por meio de bolsa de doutorado.

\section{Referências Bibliográficas}

[1] FEDELE, R. Soldagem de tubulações: metalurgia, procedimentos e desafios, Metalurgia \& Materiais, v.58, n.521, 2002.

[2] GORNI, A.A., SILVEIRA, J.H.D., REIS, J.S. Metalurgia dos aços microligados usados na fabricação de tubos soldados com grande diâmetro. Tubo \& Companhia, v.5:26, p.52-63, 2009.

[3] CALOI, G. Análise da soldabilidade do aço API 5L X-80 por meio dos testes Tekken e de implante. 145p. Dissertação (Mestrado) - Pós-Graduação em Engenharia Metalúrgica do Departamento de Ciência dos Materiais e Metalurgia Pontifícia Universidade Católica do Rio de Janeiro, Rio de Janeiro, 2008. [4] KOU, S, Welding Metallurgy, 2nd. John Wiley \& Sons, 2002. [5] ASSIS, J. T., et al. X-ray analysis of residual stress distribution in weld region, International Centre for Diffraction Data, Advances in X-ray Analysis, Volume 45, 2002.

[6] FRANCIS, J.A, et al. Transformation Temperatures and 
Welding Residual Stresses in Ferritic Steels.In: Proceedings of PVP2007 2007 ASME Pressure Vessels and Piping Division Conference July 22-26, 2007, San Antonio, Texas.

[7] BALleSTEROS, A.F., PONCIANO, J.A.C., BOTT, I.S. Susceptibilidade de juntas soldadas circunferenciais de aço API 5L X80 à corrosão sob tensão e à fragilização por hidrogênio, Tecnol. Metal. Mater. Miner., v.6, n.3, p.147-152, Jan.-Mar. 2010.

[8] MACHADO, I.G. Condução do Calor na Soldagem: Fundamentos e Aplicações. Imprensa Livre, Porto Alegre, 2000.

[9] COSTA, A.D.S.B. et al. Comparação dos níveis de tensões residuais para diferentes parâmetros utilizados no processo de soldagem tig automático em aços de tubos ASTM A106 Gr. B. Em: PDPETRO, $4^{\circ}, 2007$, Campinas.

[10] CULLITY, B.D. Elements of X-ray Diffraction, second ed., Addison-Wesley Publishing Company, 1978.

[11] LU, J., JAMES, M., ROY, G. (Ed.). Handbook of measurement of residual stresses. [S.1.]: Inc. The Fairmont Press, 1996.

[12] MARQUES, P.V., MODENESI, P.J, BRACARENSE, A.Q. SOLDAGEM - Fundamentos e Tecnologia. 3ed. Belo Horizonte, editor UFMG, 2009.

[13] GAO, H. et al. Determination of residual stress by x-ray diffraction in HSLA-100 steel weldments. Proceedings of the International Conference on Residual Stress, Linkoping, Sweden, June 1997.

[14] HAYASHI, M., ISHIWATA, M., MORII, Y. Residual stress distribuition in carbon steel pipe welded joint medasured by neutron diffraction. Materials Science Research International, vol.6, n.4, p.287-294, 2000.

[15] PARADOWSKAA, A., et al. Residual stress measurements by neutron diffraction in multi-bead welding. Physica B, v.385386, p.890-893, 2006. 